\title{
Mortality and motivations: Clinicians’ integrity engaging death within complex cultural context
}

\author{
Christopher Jenner
}

VAMC Togus, Winthrop, USA

Email: chrisjenner66@hotmail.com

Received 24 January 2013; revised 27 February 2013; accepted 5 March 2013

\begin{abstract}
This broad ranging discussion examines the clinical encounter and deconstructs psychological and cultural context and implications, finally honoring the comprehensive awareness that the clinician requires for best practice in encountering mortality. Clinicians engage client disease and dying presentions, and ultimate mortality. Communicating mortality openly or subliminally is not always conscious. Mortality awareness can produce stress and untoward behaviors. Psychological mortality avoidance, citing Kierkegaard's existential paradox, and the death (in both senses) of Joseph Campbell's cultural hero illumine socio-cultural elements including the elusive "good death", sequestration of death from society, and the concept of managing death in volume. Cultural diversity awareness and the concept of transcendence clarify outlier and hybrid cultural client presentations demanding maximal clinician flexibility. Mortality Salience Theory predicts contracted world view when confronted with mortality, demanding sensitivity to a variety of responses. A hospice approach may not be best for some, despite a lack of new alternative to that paradigm. Managing mortality awareness and dying stresses the clinician by the weight and loneliness of perhaps unpopular decisions, by responsibility to community in managing death, and by the take-home exposure of the clinician's family to the concept of death and mortality. Aptitude for managing death depends on clinician self awareness and a good match with practice venue. Clinician integrity and consciousness of motives and responses allows engagement or deferral as necessary without threat to identity.
\end{abstract}

Keywords: Death Avoidance; Mortality; Cultural Awareness

\section{INTRODUCTION}

Mortality awareness can threaten equilibrium as people and society, in simplest terms, would prefer not to think about dying. But the clinician must deal with mortality of clients and at times will encourage the client to engage as well. All clinicians deal with mortality at some level, subtly implied or frankly managed. There are times that death is subtly addressed in the clinic, in terms of risk reductions, family histories, and occasionally more directly as psychological and spiritual inquiry by both clinician and client, as with disclosure of terminal disease [1,2]; and advance directives counseling [3-5]. Quite consciously, by career choice, some invest considerably in the care of the dying, in critical care units, hospices, gerontological primary care, and nursing homes. However more or less subliminal, the concept of mortality is a constant companion to the psyche, threatening to self esteem, and to hopes and plans for meaning in life for the clinician and client alike [6-8].

An often uncomfortable topic, the clinician will choose to tackle the client's mortality directly or by implications, either intimately, or with a professional distance, or may avoid the topic altogether [9]. Often cues are taken unconsciously from the client, as full awareness can be obscured by the clinician's own responses to mortality and the clinical agenda. Where death is commonplace, as in critical care, nursing homes, and hospices, mortality sensitivity as the business of the institution may be packaged in protocols and policies [10]. For dealing with mortality in volume, clinicians may relax into prescribed clinical habits for talking about chronic disease progression, terminal diseases, and advance directives. In fact, templates for such conversations are available in the literature [11]. These best practice formulas can help the clinician achieve professional distance, and/or can act as a gateway to meaningful and deep dialogue with compassion and humanity [10,12-14]. The singular clinician is finally operant and responsible for personalizing best practice recommendations, cumulatively omitting or adding elements to the relationship through small and often unconscious decisions.

Cultural and psychological concepts illumine the conscious or unconscious choices the clinician undergoes in addressing client mortality [15]. Institutions that deal 
with mortality make those same choices through policy and mission, and mortality challenge paradigms can help analyze corporate effectiveness and sensitivity [16,17]. Clinicians, in choosing an institution or focus of practice, will differentiate according to their own responses to mortality awareness challenges; it is quite acceptable to choose an institution or culture of practice that encounters mortality infrequently. For those who may practice in saturation around mortality, critical self analysis will identify the optimal setting and role.

The issue of addressing mortality is replete with ethical consideration. Both individual choices and institutional policy structures involve beneficence in terms of honoring both cultural diversity and deviance, and non-maleficence as unconscious reactive behaviors and policy can have a limiting and untoward effect on the experiences at end-of life. Autonomy of the client choices to avoid or engage mortality awareness in the clinical relation is risked if clinician sensitivity and flexibility of approach is not optimized. Most importantly, clinician and institutional integrity demands maximal consciousness of all the choices made: subliminal reference to mortality, direct conversations about mortality, and even with regard to choice of institution and culture of clinical practice. Furthermore, health care generally has the social obligation to manage death with flexibility and sensitivity to both common and uncommon presentations, however strange or obscure they may seem [13]. Ultimately the clinician will choose to engage or not. If the choice is conscious, the encounter is on firm ethical ground [13].

Consciousness, however, is an investment of time, social rearrangements, risk of loneliness, and sometimes criticism [18]. Not every clinician is culturally or psychologically suited to diverse mortality awareness saturation, and the best of these will know their limits. It may be said, then, that the true choice is whether a clinician is able and willing to self-assess mortality awareness challenges to become fully aware and effective. These persons will exemplify best practice in care of the very ill and dying, and of the living as well. Mortality and death anxiety are, after all, woven together with all the experience of living [6,8,19-21].

This broad ranging discussion examines the clinical encounter and deconstructs psychological and cultural context and implications, finally honoring the comprehensive awareness that the clinician requires for best practice in encountering mortality.

\section{THE CLINICAL ENCOUNTER}

\subsection{Whom Does the Mortality Conversation Benefit?}

The exercise of clinical power in the clinician/client rela- tionship includes directing a conversation. Client education as a concept sets up the dynamic in advance, and the reverse relationship is the exception. The clinician always has an agenda, ethical or institutional, to promote accepted healthy behaviors, encourage understanding the terminal nature of a medical condition, or obtain a working document for procedures or directives. The client is not as accountable to an institutional standard in the relation, and generally has more freedom as the information consumer. The consumer rights are strongly defended in modern medicine, and the client choice to deny or defer any topic is generally honored. Talking about death may therefore benefit the clinician in fulfillment of duty, but it may suit the client personally to defer. Another scenario may have a client who is suffering death anxiety demand a conversation that a clinician may wish to avoid or obfuscate in order to avoid over-committing an opinion. That motivations to deny or defer engaging mortality awareness are often below immediate consciousness makes them no less powerful or important $[1,22]$.

\subsection{The Problem of Best Practice}

The concern of best practice in matters of psychological and spiritual density is ethnic sensitivity and flexibility. Deconstructing mortality in its contextual implications is a multidimensional problem and ancient, and how medicine manages death is not a convenient historical evolution $[6,20]$. Any formula to handle the issue is still necessarily premature, and must be tentative and optional. Nevertheless, clinical recommendations for cardiovascular disease, for diabetes management, for cancer screening and others all imply that there is a risk of death that is higher for affected persons. A callous treatment of this implication can be damaging [23]. Rather than rely blindly on scripted templates, consensus guidelines, and multicenter randomized controlled trials, the clinical handling of mortality awareness will ever be an individual matter requiring concern and tact. To the degree that valid best practice recommendations simply imply mortality, as with mortality risk reduction advocacy, the unconscious density of the topic requires conscious honor, and the self-aware clinician will manifest superior integrity and efficacy. But one's attitudes and responses to death and dying are not simple to evaluate, as they are rooted in the psyche and socio-cultural contexts [6,7,17,24].

\section{DEATH AND SOCIETY}

\subsection{The Social Contract}

Jean-Jacque Rousseau described in his $18^{\text {th }}$ century seminal treatise [25] the derivation of social and political normative behavior. Man offers a degree of freedom in exchange for a degree of security. For mortality, cultures 
likewise subscribe to a communal conceptualization that offers some security beyond psychologically risky independence of thought. That Rousseau ended an intellectual outcast illumines a darker side of the unconscious collective social contract. It suits modern man as well to be comfortable in common values and behaviors regarding mortality, and the risk to outliers of thought and action are as they were for Rousseau.

The theoretical exchange of freedom and diversity for security and commonality anticipates the rise of cultures, nations, and western thought. Fascism, ethnocentrism, and bigotry are examples of the worst effects; disaster relief, religious tolerance, and full suffrage are among the best. Cultural, national, or ethnic responses to death and dying are also built over years, and they reflect a social contract to share what may at worst be an unconscious limited and contracted view, or at best may consciously encourage a maximally flexible approach. A culture can well be judged by its attitudes to death and dying, as the issue is a core problem of human existence $[17,21,24$, 26-28].

\subsection{Existential Paradox}

Kierkegaard $[6,29]$ describes man as finite experiencing the infinite, or the mortal experiencing the immortal. Man, among animals, conceives truth and divinity that supersede his own life, and man becomes connected to the eternal through spirit, love, and accomplishment. Yet it is incompatible that the human be mortal and immortal at once, and responses to the conflict determine the individual. Camus, in The Myth of Sisyphus [30] goes further to explain that the continual struggle to assert an lasting (immortal) influence on the world, the symbol of pushing a rock uphill only to have it eternally roll back down before reaching the symbolic and elusive height, is the legitimate, laudable, and fulfilling enterprise of being alive and conscious. The "myth" is that Sisyphus is eternally unhappy. For the existentialist, or perhaps Maslow's actualized man [31], the paradox of finite life appreciating, approaching, and ultimately and repeatedly failing the infinite is the sufficient ethos of life. Societies prescribe the measures of success in handling the existential paradox. The cultural hero archetype personifies highest ranking in death and dying for each culture.

\subsection{Death of the Hero}

Every society honors the man who succeeds in the infinite- the hero who has achieved a symbolic immortality, or died valiantly in the effort. The stories often recount a transcendent death or an immortal accomplishment. Such a tale (fact or fiction, unknown, or both) may form the basis of a religion, a tradition, a habit, or simply an unconscious sublime yearning. Dying for home, country, love, or other eternal concept is the ultimate mark of the cultural hero. Statues are raised in the material and/or in the psychological sense, and allusions to a great life (and death) that populate literature, religion, or even conversations in the medical clinic are examplar in society of a how to die. These cultural templates affect client and clinician alike at a very deep level. If, as globalism, the depersonalization and unpopularity of war, the narcissism inherent in capitalist society, and the sequestering of dying persons in institutions affects modern western culture, the iconic Death of the Hero is itself dying, a psychic void remains, symbolic of disorientation in cultural and individual mortality awareness [6,32]. Attention to the cultural responses to death are revealing: half-masted flags, detective dramas, embryonic research, 9/11 benefits, Rambo, Princess Diana, Osama bin Laden, and more humane slaughterhouses. The diversity of interest may seem random, but is certainly very enthusiastic. More usual manifestations of cultural response to dying are memorial services and memorials, funeral conventions, regulations around deaths in institutions, autopsy, and coroner investigations. Honoring the dead seems suffused with policy, ritual, and conventions that, while often short of encouraging, at least allows the variably conscious idea of fallen hero for succor of the grieving.

\subsection{Good Death}

Yet, what constitutes a modern "good" death is less and less tied to deep cultural history as prescribed by the iconic hero. Modernity propounds diversity, openmindedness, and individual freedom. Hospice, in particular, displays cultural tolerance as a totem. KueblerRoss's stages of death [33,34] provide a benchmark for managing the modern death. It is interesting to note, however, that historically, diverse iconic deaths, like Davey Crockett, John Henry, James Dean, Billy the Kid, samurai warriors, and Jack Kerouac have not ended in peaceful acceptance, and are deaths celebrating denial of mortality, like Sisyphus starting back up the hill yet again. But, the hospice iconic death is gradual, submissive, peaceful, and introspective. The power of the defiant or resistant death, or certainly of self-administered death, in modern cultural psyche is not honored well in hospice or Kuebler-Ross. Numerous authors have wondered that acceptance and the peaceful calm at end-oflife adopted by hospice may be less than a ubiquitous goal [12,26,35-39].

\subsection{Sequestering Death}

So, perhaps peaceful introspective acceptance is not, after all, the final common pathway for a good death. Despite the desired protected transition in the bosom of family that clinicians in institutions for dying provide for 
their client's, many individuals value the classic hero's deaths, or may prefer to go quickly, even if violently, so as not to experience the pain (or existential paradox) of dying. The time necessary to move through KueblerRoss's stages of grief may not be desirable to many persons. But the paradigm for hospice, once itself a new alternative to hospitalized death and tailored to the more predictable course of cancer-related dying, is now become a widely accepted and a more corporate, institutionalized process. That hospice benefits have become a mainstream institution and are seen as under-used [40] can conceivably tempt clinicians to advocate the system for persons who may not otherwise accept a purely palliative approach. Qualifying for compensation may require adjustment of values, and restriction of clinical options. Furthermore, there is temptation for a clinician to hand-off a clinically difficult patient. Where the illness is not easily or rewardingly tractable, the death may be. Convincing a client toward a hospice approach can be ethically suspect, even if motives are unconscious. Hospice approach and orders withholding treatment can be revoked, but only with revisiting the heavy weight of mortality awareness yet again, which becomes exhausting to everyone involved.

Hospice at home is held most desirable, but individually modern economics and practical concerns may require that persons do not have adequate supports for dying at home. It is ultimately, however, a collective value that prescribes that society has not made death at home a priority. It is then certainly convenient to have the dying and death handled by professionals, even though it is expensive. A peaceful controlled death is obviously in the interest of an institution that handles death in volume. Kuebler-Ross is a good fit there, but a clinician of integrity will recognize the limits of the hospice approach [36].

\subsection{Safety in Numbers}

For society in total, perhaps the idea of death in volume is easier to handle. A tragedy becomes depersonalized and the smells, sights, and noise of death are become general concepts rather than intruding sensation when the personality of the dying is not addressed [13,41]. Modern society is exposed to death as a collective concept constantly in video games, movies, newscasts, and hospice fund-raisers [26]. In addition, media sensationalizing of public death events anticipates a dramatic response, but ultimately inures responses through habituation. Clinicians, too, are in danger of both collectivizing their experience of death and of a decreased personal response through habituation. The hospice movement, originally countering medicalized death, is itself becoming more institutional [8]. Transfers from the acute wards to hospice and palliative wards are becoming more effi- cient, which certainly accelerates palliation, but risks dehumanizing clinical particulars. Crassly put, the acute clinician "washes his hands" on leaving the bedside, as the hospice personnel "gown up" to assume care and acute care-based problems are forgotten [42]. The "death specialist” working in palliative and hospice care will need to be especially sensitive to volume induced depersonalization of care. Ideally, the acute clinician and the palliative clinician symbiose.

\section{DEATH AND THE SPIRIT}

\subsection{Cultural Awareness}

Diversity awareness is a national mandate in health care: literature, treatises, and legislation burgeon. For many clinicians the awareness amounts to being aware that there is a mandate. In corporate ethnic diversity training, some disturbing studies have shown problems of effectiveness and even some paradoxical bigotry [43-45]. For some communities, ethnic diversity really exists, and clinicians have to respond ethically and legally. But problems exist in cultures that are homogenous or rural when a spiritual person presents who does not fit the local cultural mold. Cultural awareness generally does not address the idiopath within a given culture, but focuses on a brief and concise type-cast [3,46,47]. In addition, modern persons may assimilate elements of many cultures into a personalized hybrid. Catholics may practice Zen meditation and Protestants may read their horoscopes faithfully. Being culturally aware more and more signifies a philosophical study of the bases of culture and the function of the elements of culture rather than memorizing cultural stereotypes.

\subsection{Transcendence}

Most cultures seek an explanation for the paradox of mortality experiencing the immortal. Resurrection, reincarnation, ancestor worship, cryogenics and re-animation, building a pyramid, having children, writing a book are all charged with the spiritual $[20,46]$. The secular and the sacred seem all to desire a way out of mortality. To claim some lasting influence beyond death is the nature of humanity $[6,29,30]$. The clinician should understand this primal and insistent need at the end-of-life. Uncovering the particulars of a person's life worth requires time, skill, and effort. A key concept in these investigations is honor, both conversational and ritual. The expert clinician is easily identified in that these investigations occur with every patient.

\section{DEATH AND THE INDIVIDUAL}

\section{The Problem of the Outlier}

Surely the approaches to the paradox of mortality are 
individual and cultural. But consider that modern western thinking, cultures and polities value consensus in decisions through dialectic. Mostly dualist, it is a rare society that respects a third opinion for very long. American dissent is ultimately bipartisan; socialism, progressivism, green movements, and other "third" players become largely unimportant in the final consensus, except as they may garner or detract support from the more established binary elements of the political culture.

For a culturally acceptable modern death, the traditional binary option of the last twenty years has been the peaceful death of Kuebler-Ross at home or hospice against and originally a reaction to the then prevailing medical cure-based management paradigm of the acute care hospital [24]. As hospice becomes more prevalent and more universally accepted, the dialectic slows. Alternatives to hospice as the newly institutionalized death paradigm for the last ten years, is a yet undiscovered realm. But it is dialectic and dissent that challenge society to best behaviors. The astute clinician will pay close attention to outlier concepts like assisted suicide, euthanasia, violent death (immolation, gang deaths), and desperate struggle at death that are not as honored. Each of these concepts has held high societal respect in other cultures. A prevalence of even more deviant deaths such as serial killings, snuff films, violent or drug related suicide, and death by family violence also attest to a grotesque cultural misalignment around mortality. Here the uniformity of societal mortality awareness response is starkly revealed, and the clinician must certainly selfassess reactions against these challenges. When an individual may opt (consciously or unconsciously) for an unpopular death, society and the immediate people, including clinicians, surrounding that person are judged for their flexibility of thought and behaviors [5,12,13,37,39,48].

\section{TERROR MANAGEMENT THEORY}

\subsection{Mortality Salience}

Earnest Becker's Denial of Death (1973) examines a subconscious motivation to avoid thinking about mortality. The paradox of having to die despite appreciating the immortal divine is incompatible with functioning. As a result, unconscious efforts are made to avoid the subject of mortality or mortality salience. This explains the sequestering of death in society, the difficulty of broaching the topic in a clinical situation, the desperation of last resort therapies, as well as the seeming irrationality of risky behavior against clinical advice. Terror Management Theory in Sociology strives to discern the function of mortality salience in human behavior. Predicting individual reactions to the conscious or subconscious awareness of mortality can be studied in this model. Clinicians should understand that warning against a risk behavior may have paradoxical results. A client may unconsciously take risks to assert his immortality [19,22,49].

Significantly, a person's culturally valued norms become more constrictive and may be rigorously defended when even unconscious mortality awareness is unavoidable, as those norms offer legitimacy against the existential paradox [50]. For dying, this unconscious reactionism requires at least symbolic "bosom of family" to maintain psychic security. This constriction and defense of world view has implications for clinical care, for the client, and the phenomenon can be true for the clinician as well. An awareness of mortality may reinforce a more limited clinical paradigm, such as the stages of grief, or cardiopulmonary resuscitation protocols (to pick two extremes). Any clinician confronted with issues of mortality should know the risk of unconsciously constricted clinical thinking.

\subsection{Habituation}

Some studies have shown older persons are less vulnerable to the rigors of mortality salience due possibly to exposure to the possibility of death for a longer period of time [5,22]. It simply ceases to be threatening. Clearly, however family, friends, and society will not have that benefit when confronted with the individual's mortality at end-of life. Constricted world view and defensive behavior from family members can be anticipated. Likewise, the clinician will be encouraged to feel immune due to habituation, but must nonetheless operate in the context of family, friends, and colleagues who may not have that protection. And, for both the client and clinician, death anxiety and mortality awareness can present suddenly, and cumulatively. Maintaining integrity during repeated exposures to, or saturation in, the death experience can be especially stressful.

\subsection{Self Esteem}

A key protection against the unconscious rigors of the mortality salience effect is self esteem. It has been shown that persons with higher self esteem are less likely to constrict world view in reaction to mortality salience. This implies that the perception of life achievement, seen psychologically as a transcending immortal construct by the mortal human, diffuses the unconscious response. These persons are likely to be more comfortable in their own world view, less defensive, and more accepting of others $[19,31]$. These are those persons who may be good candidates for the self-actualized peaceful acceptance of death Kuebler-Ross describes.

\subsection{When We Are Wrong}

A modern man may want to die like Davey Crockett, manipulating stocks on his laptop until the end. A hos- 
pice-based peaceful dying in the arms of family may be depressing to him. Another man may need to know his religious view is literally correct as he dies, and a culturally diverse atmosphere may make him angry and defiant. A woman may crave secular privacy and is confronted by a family that wants her to return to the religion of her youth. A young man may want to die in the terms a street gang honors, battling with gun or knife, and instead is dying quietly in a hospital ward. A woman may find honor in her suffering, and a man may be disgusted by his own suffering or vice-versa. Surely the clinician has a role helping these diverse peoples to die well. The choice to manage these deaths must be done with full awareness and understanding, as many persons around the client will be disturbed and upset. But, the good death is various, and even the unusual is valid and honorable in the context of psychological and cultural significance for the individual $[11,26,35,36,47,48]$.

\section{DEATH AND THE CLINICIAN}

\subsection{Integrity}

Self awareness is the mark of integrity, a prime ethical concept in modern medicine. Decisions are made with maximal knowledge of motive and consequence. For the self-integrated clinician, a consistency and clarity of thought and values requires ferreting out those internal doubts, fears, and reactionism that obscure sensitivity for the client's needs. The clinician's religion (or more broadly, spiritual identification), world view, social ambition, professional ambition, and, to the greatest extent possible, subconscious motivations should be illumined and deconstructed. It is certainly not unreasonable to seek advice or even professional counseling in the effort. There will not consistently be, even then, a relational fit for every client, but self awareness allows detachment and the option of referral without loss of esteem and ego. The subject of death and dying, as has been discussed, can magnify any inconsistency.

\subsection{Plurality, Inter-Faith, and Assimilation}

A clinician may work in an institution that holds compatible values and world view, as in the traditional stereotype of Catholic charity hospital. In this scenario, an outside clinician will be asked to assimilate or conform to the world view the institution proscribes. Another model is referred to in religion as inter-faith or ecumenical practice, but may be a philosophy or theory as well. In this institutional construct, various world views are invited to join in common experience. In this approach, tolerance is the operating principle and, as has been said, it may be difficult for those persons who are unsure of their own worth, clinicians included. This model constitutes most hospice institutions. Any reason- able approach is tolerated to a less or greater degree. Finally, the most challenging model for the clinician is the principle of plurality. Each world view, even if there is only a single subscriber, is not only tolerated, but also given the space, conditions, equipment, and legitimacy it requires [51]. Because persons dealing with mortality will react strongly against a perceived breach of their own world view, in an environment where any cultures may be exercised enthusiastically, conflict is possible. The clinician here must be astute, secure, and creative. It is wise not to assume these attributes lightly as harm is easily done through precocity.

\section{CONCLUSIONS}

\subsection{The Density of Decision}

Talking about death can trigger an unconscious response in the clinician and the client. All clinicians will have to decide if and how to introduce mortality in the client relationship. Certainly a conscious decision is preferred. Cultural norms for dying are psychologically active and limited, and modern hybrids of many societies mixing together may not protect the individual from existential suffering as well as traditional archetypes. And so, cultural awareness and tolerance is required, but is no longer the highest standard; an understanding of the function of culture is stronger.

The individual risks feelings of anxiety to even an implied challenge around mortality, as does the clinician. All clinicians must know their limits to personal and professional integrity well enough to defer or disengage without loss of ego or self-esteem.

For those who are working around death and mortality as a career choice, the most self-integrated clinicians stand to be outstanding persons in the creation of good deaths for clients. This role, well suited to the holistic Gerontologist and especially to the Nurse Practitioner who has both a holistic educational framework and the authority to direct care, is among the most valuable in modern medicine.

Death is bereft of its traditional context as cultures meld, integrate, and disintegrate [32]. Hospice is becoming a largely unchallenged institutional paradigm that offers a non-specific cultural acceptance model but may be constricted conceptually and depersonalizing in subtle ways. The integrity of the clinician, and of health care in total, demands a knowing and unrelenting enthusiasm in diversity, over and above simple acceptance, as death struggles to find its human expression in each unique person.

\subsection{Loneliness of Decision}

Helping the dying involves the loss of the most important colleague-the client. In addition, there are few who will 
understand if the clinician advocates against a culturally or institutionally entrenched normative death and dying construct. As has been said, the reaction from persons about an issue concerning mortality will be a constricted and defensive world view. A creative leader in death and dying management will necessarily have some enemies and will need to learn to be alone at times.

\subsection{The Clinician in Society}

\subsubsection{Work}

Camaraderie is important to most persons. It is sometimes effective to agree with cultural norms in order to feel secure. Advocacy for the outlier may trump that option, and work relations may be tense. As scientists, medical persons will understand results, however, and a good death will eventually be honored. Choosing an institution in which to practice is part of the clinician's self analysis. The confines of one's thinking determine personal security and a range of effectiveness. In fact, a limited world view can be very effective indeed in the right environment; a clinician with a specific spiritual construct is liable to provide well for client's who share that construct. An honest appraisal should not be embarrassing —it is much more limiting not to know one's limits.

\subsubsection{Family}

The clinician's family is a cultural construct as well. And that death awareness from the worksite is an unconscious real mortality challenge for each member of the family is undeniable. For the clinician, as well as the client, family members and others at home will not have equivalent self esteem to protect against the challenge. For a clinician to serve well at work in a position of responsibility and public trust, threatened home world view may become an ethical issue. The difficulties for each person in the clinician's realm, as in the client's, will be valid and genuine, and in the ultimate pluralist view, there is no bad or wrong adaptation. As a result, the very best clinicians in death and dying will likely need to be a clinician of a sort at home, managing mortality salience as a complete life effort.

\subsubsection{Community}

Finally, the clinician, in dealing with matters of death and dying, stands to provide the ultimate service for community. Community needs to preserve function despite the existential paradox: the reality of death against the drive for lasting and transcendent achievement. Trying to build lasting value as a culture and community, we must be safe from the paralysis of fear of death. Irrational risks or depression are the symptoms of a community that feels threatened and unsafe. Part of safety is comfort in normative restrictions for thinking and behavior. The shared world view is essential for these persons.
For a few others a calm awareness and actualized self esteem allow more freedom of thought. There must be processes for both the culturally restricted (though not at all less honorable) and for the more confident acceptance responses to mortality.

Finally, there are ever outliers in any society who will continually challenge even the most resilient clinicians' thinking and creativity with new, unforeseen presentations, views about death, and problems of cultural context. More than the culturally restricted normative, or the culturally open accepting, these persons make the decision to serve in the arena of death and dying most intense.

\subsection{Answering the Question}

How and whether to address mortality is a client-specific and clinician-specific question. The original decision to enter a health care profession is personal and not without risk; to some degree, any clinician will imply and subtly suggest to a client their mortality. But, the decision to work intensively with death and dying requires an even deeper commitment to flexibility of thinking, to resilience, and to client autonomy. If indicated, the decision to limit exposure to mortality awareness or the stresses of multi cultural conflict is certainly as valid and honorable as the decision to engage. Through a thorough introspection, a clinician will find a sense of self and a feel for where best to apply talents and knowledge. It is managing death that most profoundly requires psychological aptitude. It is best not to engage without clear evidence of one's own abilities, discerned through conscious and intentional introspection.

George Smith, in an address to the Maine Health Care Association in 1995 [5] identifies intimacy, activity, coping, and social death as major concepts in the care of dying persons. Proscribing increased clinician awareness and engagement, he ends his paper thusly: "Who says that the only way for caregivers to cope is to come up with mechanisms that promote distance rather than intimacy?” In contrast, Randall and Downie [13] warn "Our point is that 'peaceful acceptance' is not encouraged by intrusive and unwanted probing into the patient's private world". These discriminations and sensitivities are personal and exhausting. There is no formula; for each client, the clinician is navigating into unknown spaces potentially filled with anxiety and dread. For a modern death and dying involved clinician, an interior sense of honor for cultural value and an intense personal integrity is still and always consciously accessed and consulted.

\section{REFERENCES}

[1] Peretti-Watel, P., Bendiane, M., Obadia, Y., Lapiana, J., Galinier, A., Pegliasco, H., et al. (2005) Disclosure of 
prognosis to terminally ill patients: Attitudes and practices among French physicians. Journal of Palliative Medicine, 8, 280-290. doi:10.1089/jpm.2005.8.280

[2] Tse, C., Chong, A. and Fok, S. (2003) Breaking bad news: A Chinese perspective. Palliative Medicine, 17, 339-343. doi:10.1191/0269216303pm751oa

[3] Froggatt, K. (1997) Rites of passage and the hospice culture. Mortality, 2, 123-136. doi:10.1080/713685862

[4] Ardeldt, M. (2003) Wisdom, religiosity, purpose, and death attitudes of hospice patients, nursing home residents, and community-dwelling elders. The Annual Meeting of the American Sociological Association, Atlanta, 16 August 2003.

[5] Smith, G.S. (1995) How well are we doing with dying? Maine Health Care Association Symposium, Sunday River.

[6] Becker, E. (1973) Denial of death. Simon and Schuster, New York.

[7] Marrone, R. (1999) Dying, mourning, and spirituality: A psychological perspective. Death Studies, 23, 495-519. doi:10.1080/074811899200858

[8] Neimeyer, R.A. (2008) Death anxiety. http://64.233.169.104/search?q=cache:ZQWncGaZF_4J: web.mac.com/neimeyer/iWeb/Site/Scholarship files/Dea th\%2520Anxiety.doc+Neimeyer+death+anxiety\&hl=en\& $\mathrm{ct}=\mathrm{clnk} \& \mathrm{~cd}=2 \& \mathrm{gl}=\mathrm{us}$

[9] Griffie, J., Nelson-Marten, P. and Muchka, S. (2004) Acknowledging the "elephant": Communication in palliative care: Speaking the unspeakable when death is imminent. American Journal of Nursing, 104, 48-58. doi:10.1097/00000446-200401000-00019

[10] Eggly, S., Penner, L., Albrecht, T., Foster, T., Naughton, M., Peterson, A. and Ruckdeschel, J. (2006) Discussing bad news in the oncology clinic: Rethinking current guidelines. Journal of Clinical Oncology, 24, 716-719. doi:10.1200/JCO.2005.03.0577

[11] University of Washington School of Medicine (2008) End-of-life issues: What is a good death: A medical perspective? Ethics in Medicine. http://depts.washington.edu/bioethx/topics/eol.html\#ques1

[12] MacDonald, D. (1992) Hospice patients without primary care givers: A critique of prevailing intervention strategies. Home Healthcare Nurse, 10, 24-26. doi:10.1097/00004045-199201000-00006

[13] Randall, F. and Downie, R.S. (2006) The Philosophy of palliative care: Critique and reconstruction. Oxford University Press, Oxford. doi:10.1093/acprof:oso/9780198567363.001.0001

[14] Ellershaw, J. and Ward, C. (2003) Care of the dying patient: the last hours or days of life. BMJ, 326, 30-34. doi:10.1136/bmj.326.7379.30

[15] Zimmermann, C. and Rodin, G. (2004) The denial of death thesis: Sociological critique and implications for palliative care. Palliative Medicine, 18, 121-128.

[16] Kaufman, S.R. (2005) A time to die: How American hospitals shape the end of life. Scribner, New York.

[17] Rich, B.A. (2003) Reflections on the social construction of death. The Journal of Legal Medicine, 24, 233-240. $\underline{\text { doi:10.1080/713832156 }}$
[18] Peck, M.S. (1978) The road less traveled. Simon \& Schuster, New York.

[19] Bassett, J. (2007) Psychological defenses against death anxiety: Integrating terror management theory and firestone's separation theory. Death Studies, 31, 727-750. doi:10.1080/07481180701490628

[20] Eisenstein, C. (2008) Life, death and the struggle against the world. The Ascent of Humanity. http://www.ascentofhumanity.com/chapter5-3.php

[21] Devries, R.G. (1979) Birth and death: The social construction of cosmic status passage. Annual Meeting of American Sociological Association, Boston, 27-31 August.

[22] Taubman-Ben-Ari, O. and Findler, L. (2005) Proximal and distal effects of mortality salience on willingness to engage in health promoting behavior along the life span. Psychology \& Health, 20, 303-318. doi:10.1080/08870440512331317661

[23] Arndt, J., Routledge, C. and Goldenberg, J. (2006) Predicting proximal health responses to reminders of death: The influence of coping style and health optimism. Psychology \& Health, 21, 593-614. doi:10.1080/14768320500537662

[24] Seale, C. (1998) Constructing death. The sociology of dying and bereavement. Cambridge University Press, Cambridge.

[25] Rousseau, J. (1765) Cole, G.D.H., Trans. (2005) The social contract. Barnes and Noble, New York.

[26] Timmermans, S. (2005) Death brokering: Constructing culturally appropriate deaths. Sociology of Health and Illness, 27, 993-1013. doi:10.1111/j.1467-9566.2005.00467.x

[27] Berta, P. (2007) Death as empirical taboo and the consequent ambivalence; the concept of death as social product. Afterlife in the Cross-Cultural Perspective Forum. Encyclopedia of Death and Dying.

http://www.deathreference.com/A-Bi/Afterlife-in-CrossCultural-Perspective.html

[28] Devries, R.G. (1981) Birth and death: Social construction at the poles of existence. Social Forces, 59, 1074-1093.

[29] Kierkegaard, S. (1963) Sickness unto death. http://books.google.com/books?id=eeOMT5Sm4dwC\&d q=sickness+unto+death\&pg=PP1\&ots=i_vts3vLt7\&sourc $\mathrm{e}=$ bn\&sig=vmjUSRlpvpwpXCL97Q9e6kvWM6w\&hl=e

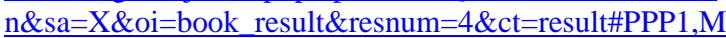
$\underline{1}$

[30] Camus, A. (1942) The myth of Sisyphus. Penguin, New York.

[31] Maslow, A. (1973) Theory of human motivation. In: Lowry, R.J., Ed., Dominance, Self-Esteem, Self-Actualization: Germinal Papers of A. H. Maslow, Brooks/Cole, Pacific Grove.

[32] Campbell, J. (1968) The hero with a thousand faces. 2nd Edition, Bollingen, Princeton.

[33] Kuebler-Ross, E. (1969) On death and dying. Scribner, New York.

[34] Kuebler-Ross, E. and Kessler, D. (2003) On grief and grieving: Finding the meaning of grief through the five 
stages of loss. Scribner, New York.

[35] Curtis, M. (2003) What is a good death?: Death cannot be tamed. BMJ, 327, 1047. doi:10.1136/bmj.327.7422.1047-b

[36] Hart, B., Sainsbury, P. and Short, S. (1998) A sociological critique of the "good death". Mortality, 3, 65-77. doi:10.1080/713685884

[37] Hendin, H. (1995) Selling death and dignity. International Task Force on Euthanasia and Assisted Suicide. http://www.internationaltaskforce.org/selling.htm

[38] Jones, J. (2003) Letter: In search of a good death: What is a good death? BMJ, 327, 224. doi:10.1136/bmj.327.7408.224

[39] RADAR (2008) Assisted dying: The facts. www.radar.org.uk

[40] National Hospice and Palliative Care Organization (2007) NHPCA facts and figures: Hospice in America. www.nhpco.org/research

[41] Gorer, G. (1965) Death grief and mourning. Cresset, London.

[42] Clark, D. (2002) Between hope and acceptance: The medicalization of dying. BMJ, 324, 905-907. doi:10.1136/bmj.324.7342.905

[43] Doorenbos, A.Z., Schim, S.M., Benkert, R. and Borse, N.N. (2005) Psychometric evaluation of the cultural competence assessment instrument among healthcare providers. Nursing Research, 54, 324-331. doi:10.1097/00006199-200509000-00006
[44] Walzer, P. (2008) Mandatory diversity training may do more harm than good. The Virginian-Pilot. http://hamptonroads.com/node/482963

[45] Kalev, A., Dobbin, F. and Kelly, E. (2006) Best practices or best guesses? Assessing the efficacy of corporate affirmative action and diversity policies. American Sociological Review, 71, 589-617. doi: $10.1177 / 000312240607100404$

[46] Beliefnet (2008) Transition rituals; death rites for major world religions. http://www.beliefnet.com/story/78/story_7894.html

[47] Beshai, J.A. (2008) Are cross-cultural comparisons of norms on death anxiety valid? Omega, 57, 299-313.

[48] Ostaseki, F. (2008) Zen and the good death. Zen Hospice Project.

http://www.amitabhahospice.org/public/spiritual support/ zen_and the_good_death.php

[49] Mosher, C. and Danoff-Burg S. (2007) Death anxiety and cancer-related stigma: A terror management analysis. Death Studies, 31, 885-907. doi:10.1080/07481180701603360

[50] Florian, V., Mikulincer, M. and Hirschberger, G. (2001) An existentialist view on mortality salience effects: Personal hardiness, death-thought accessibility, and cultural worldview defense. British Journal of Social Psychology, 40, 437-453. doi:10.1348/014466601164911

[51] Smith, W. (2008) Unpublished interview. Togus Veterans Administration Medical Center, Augusta. 